\title{
Erratum to: ULF Cell-a Novel Design Principle for Pneumatic Froth Flotation Apparatus Utilizing Uniform Laminar Flow
}

Janez Susa ${ }^{1}$ and Rüdiger B. Richter ${ }^{2,3}$

${ }^{1}$ ARCANOE Consulting, Koper, Slovenia

${ }^{2}$ Competence Center Waste Treatment, Disposal and NORM in Bauer Resources, BAUER Emirates Environment Abu Dhabi, Abu Dhabi City, United Arab Emirates

${ }^{3}$ Chair of Mineral Processing, Montanuniversitat Leoben, Leoben, Austria

Published online August 29, 2018

\section{Erratum to:}

Berg Huettenmaenn Monatsh (2018)

https://doi.org/10.1007/s00501-018-0761-5

Unfortunately, errors occurred in the original article.

The presentation of the Figs. 8, 9 and 10 and the Eqs. 23 and $33 \mathrm{~d}$ were incorrect.

The correct versions are given below.

$$
\begin{aligned}
& Q_{i n}+Q_{c a}=Q_{\text {out }}+Q_{\text {froth }} \\
& \tau_{10}=\frac{V_{10}}{Q_{c z}}=\frac{A_{c z} \cdot h_{10}}{Q_{c z}}
\end{aligned}
$$

The original article has been corrected.

\footnotetext{
The online version of the original article can be found under https://doi.org/10.1007/s00501-018-0761-5.

Dipl.-Ing. Dr. mont. R. B. Richter $(\varangle)$

Competence Center Waste Treatment, Disposal and NORM in Bauer Resources,

BAUER Emirates Environment Abu Dhabi,

15th Road (Dawi Street), Villa No. 9,

Abu Dhabi City, United Arab Emirates

ruediger.richter@bauer.de
} 
Fig. 8: Pilottest unit (Susa ULF cell), used for the execution of the flotation experiments

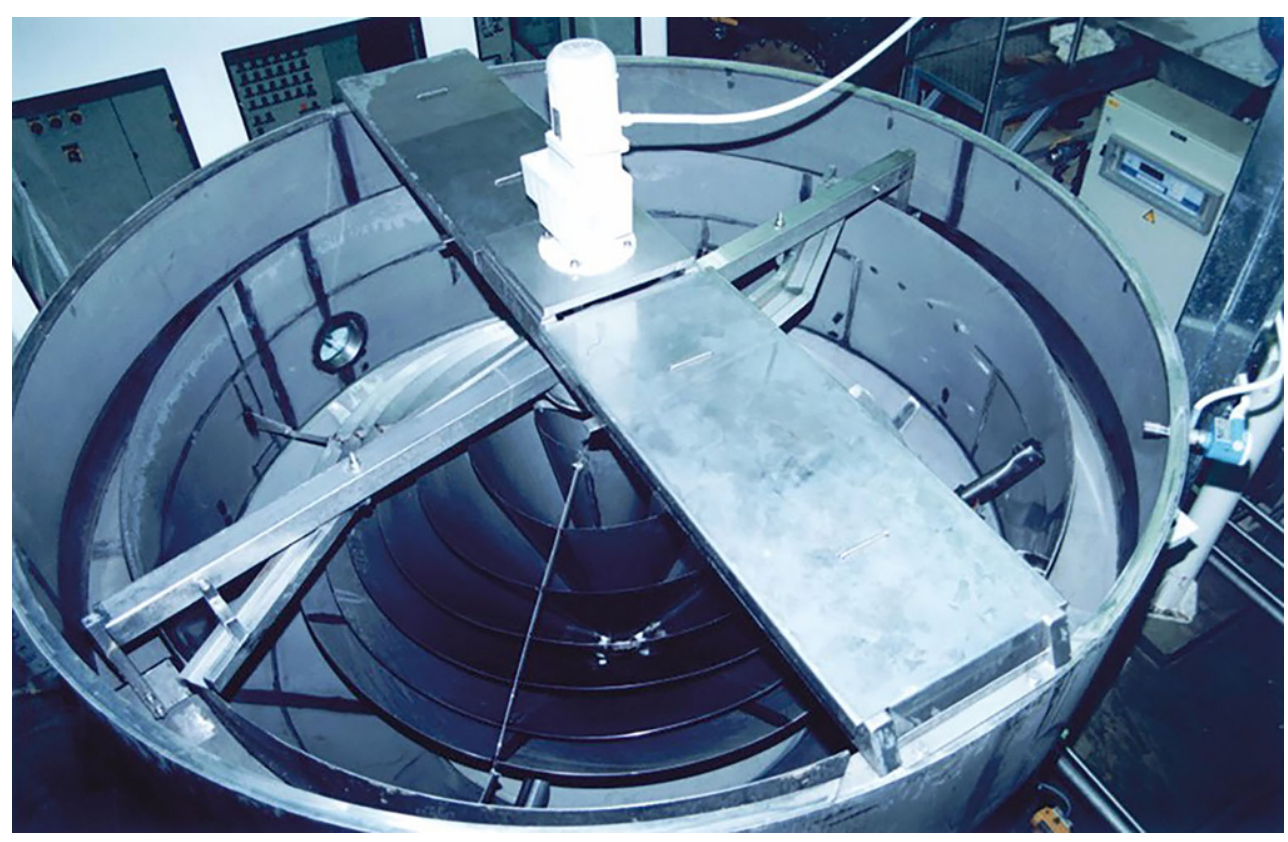

Fig. 9: Depletion (conversion) rate vs. time in minutes and depth of clarifying zone in $\mathrm{cm}$ for experiment no. 20. Linear fit of experimental points results in flotation kinetic rate of $\kappa=0.931 / \mathrm{min}$

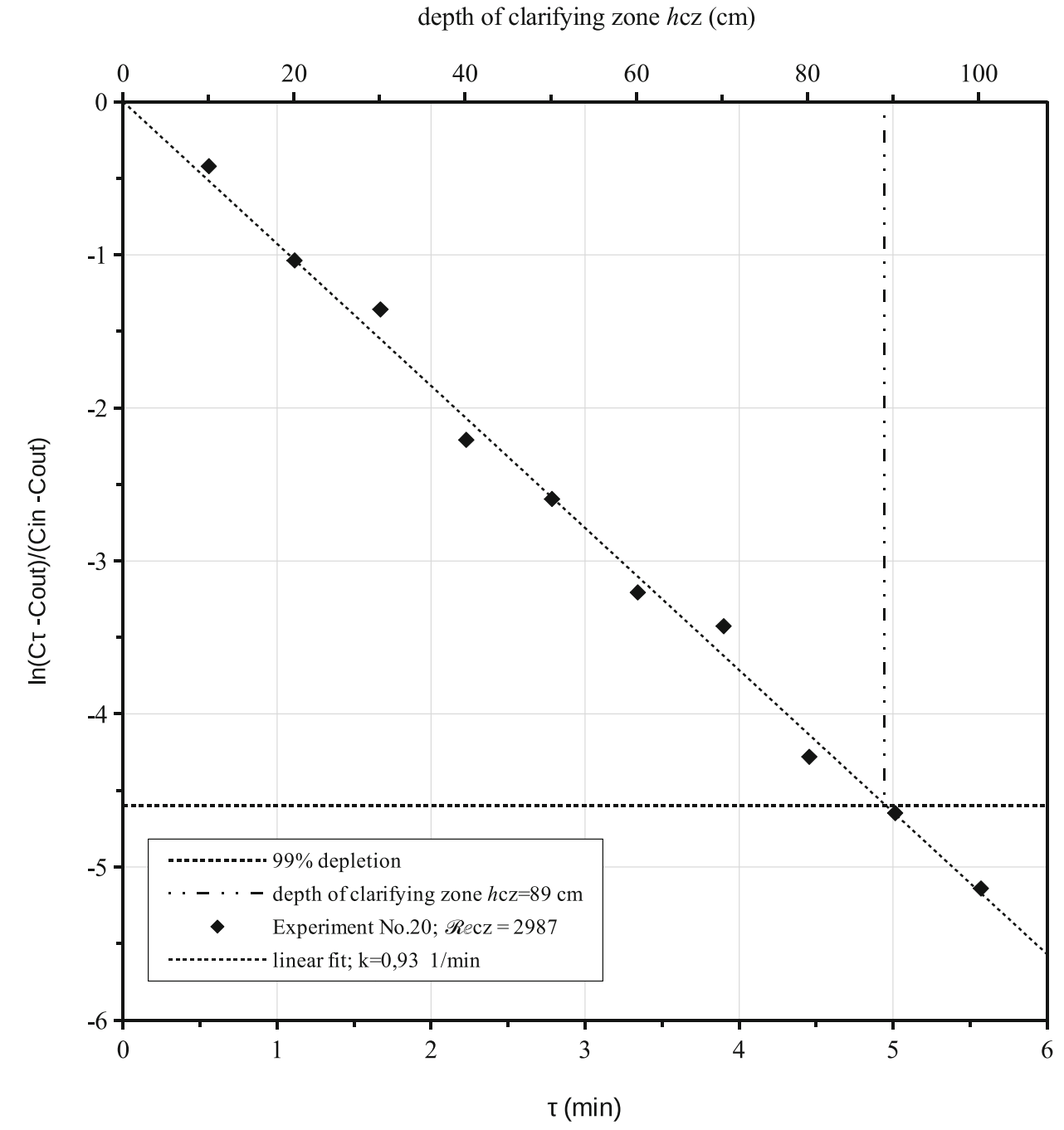


Fig. 10: Diagram of depletion (conversion) rate vs. time in minutes and depth of clarifying zone in cm for all 32 experiments

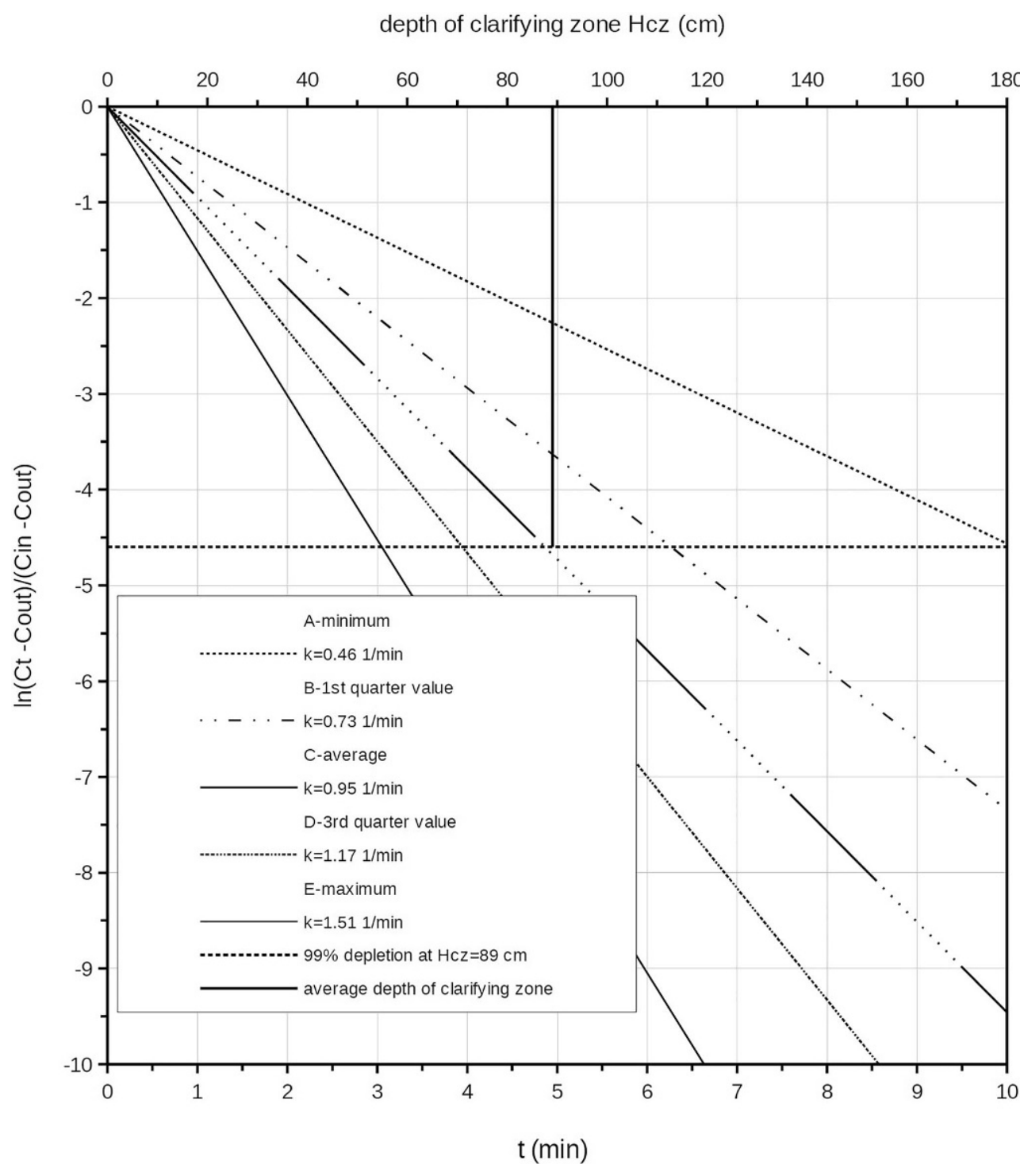

